\title{
Impactos da Covid-19 em Olinda (PE): notas etnográficas sobre pessoas com suspeita de contaminação ${ }^{1}$
}

\author{
Impacts of Covid-19 in Olinda (PE): ethnographic notes on people whith \\ suspect of contamination
}

\author{
GABRIEL FERREIRA DE BRITO \\ Mestre em sociologia pela UFPE \\ gabrielmop@hotmail.com.
}

\section{RESUMO}

O objetivo deste artigo é apresentar uma reflexão sobre a experiência de moradores e moradoras do bairro de Ouro Preto (PE) que estão lidando com a suspeita de contaminação pela Covid-19 no que tocam os diagnósticos, a prevenção e o tratamento da doença. A partir da etnografia com ênfase online, mas também a partir da observação participante, foram selecionados quatro casos diferentes para esse estudo de caso. O aporte teórico parte do pragmatismo de William James e da antropologia de Bruno Latour em diálogo com a antropologia de epidemias e da biossegurança. Os resultados encontrados indicam que a sintomatologia só é eficiente e consensual quando dentro das instituições científicas e de suas redes, mas que fora delas, os agentes se encontram em um ambiente de incertezas e dúvidas, recorrendo, às vezes por medo ou conveniência, a outras alternativas para o autodiagnóstico.

Palavras-chave: Covid-19. Etnografia-online. Experiência. Ouro Preto. Sintomatologia.

\section{ABSTRACT}

The objective of this article is to present a reflection on the experience of residents of the neighborhood of Ouro Preto (PE) who are dealing with the suspicion of contamination by Covid-19 in what concerns diagnosis, prevention, and treatment of the disease. From the ethnography with online emphasis, but also from the participant observation, four different cases were selected for this case study. The theoretical contribution is based on the pragmatism of William James and the anthropology of Bruno Latour in dialogue with the anthropology of epidemics and biosecurity. The results found indicate that symptomatology is only efficient and consensual when within scientific institutions and their networks, although outside them agents find themselves in an environment of uncertainties and doubts, sometimes resorting to other alternatives for self-diagnosis, out of fear or convenience.

Keywords: Covid-19. Online-Ethnography. Experience. Ouro-Preto. Sintomaptology.

\section{INTRODUÇÃO}

Até o último dia 31 de agosto de 2020, a Covid-19 já matou 810,599 pessoas e passou dos 23,422,070 casos confirmados. No Brasil foram 121,515 mortes e 3,910,901 casos confirmados. Enquanto alguns estados do Brasil ainda registram alta nos casos, o estado de Pernambuco, campo de pesquisa, vem oscilando entre estabilidade e, no momento, queda: são 7,593 óbitos para 125,539 casos confirmados ${ }^{2}$. O que estou tentando demonstrar é a escala global do vírus a partir de sua representação numérica ${ }^{3}$. No caso do município de Olinda, que

\footnotetext{
${ }^{1}$ Artigo recebido em 29.09.2020 e aprovado em: 20.11.2020.

${ }^{2}$ Fonte: site G1.Globo. Disponível em: https://especiais.g1.globo.com/bemestar/coronavirus/estados-brasilmortes-casos-media-movel/\#/. Acesso: 1 de setembro de 2020.

${ }^{3}$ Os números aqui não são entendidos como a única e a mais correta representação da realidade. Ao falar em contextualizar numericamente, assumo que essa é uma forma de saber sancionada, porém, não a única
} 
Rev. Interd. em Cult. e Soc. (RICS), São Luís, v. 6, n. 2, p. 156-173, jul./dez. 2020

ISSN eletrônico: $2447-6498$

tem 392, 482 pessoas, estimadas, conforme o último censo do IBGE, são 5,598 casos confirmados e 466 óbitos. Olinda é a cidade que ocupa o $5^{\circ}$ lugar no Brasil em relação a densidade demográfica; o bairro de Ouro Preto é o segundo maior da cidade e tem em torno de 30.644 mil habitantes ${ }^{4}$. O número de casos de Covid-19 até o último boletim epidemiológico do dia 30, referente ao dia 29 de agosto, é de 555 casos confirmados e 47 óbitos.

A antropologia de epidemias, da biossegurança (Cf. KECK et al, 2019 ; NADING, 2013; MACPHAIL, 2015; SEGATA; MASTRANGELO, 2020) e da microbiopolítica (PAXSON, 2008) têm lidado com a temática de doenças e de vírus para refletir sobre as relações entre saúde, ciência e poder; já a etnografia online (MILLER, 2004; HINE, 2015; LEITÃO; GOMES, 2017; RAMOS; FREITAS, 2017) tem se mostrado de grande valia para pesquisa em ambientes digitais (RAMOS; FREITAS, 2017) - e, em tempos de isolamento social, acredito que ela se tornou uma forte aliada para produção de conhecimento antropológico sobre epidemias. Mobilizar estas correntes antropológicas parece ser frutífero para pensar em como, neste caso, diferentes populações têm lidado com os impactos da Covid-19 em cada região, demonstrando, assim, como o repertório de sentidos e de experiências das pessoas se reconfigura, ora na prevenção, ora na sua politização sem que, todavia, uma alternativa esteja apartada das outras: como se buscará demonstrar, os agentes são engenhosos e criativos em suas formas de adaptação à presença do vírus.

O objetivo deste artigo é apresentar uma reflexão a partir da experiência de moradores e moradoras do bairro de Ouro Preto (PE) que estão lidando com a relação de suspeita de contaminação pela Covid-19 no que tocam os diagnósticos, a prevenção e o tratamento. Minha hipótese é de que os moradores e moradoras articulam diferentes saberes, mas, de modo geral, estão secundarizando os diagnósticos laboratoriais e clínicos devido ora ao medo da contaminação de ter que ir em uma clínica, ora por disporem de outras alternativas/saberes (autodiagnóstico e automedicação, conselhos de parentes ou pessoas conhecidas) para lidarem com a doença. Em segundo lugar, acredito que, de um ponto de visa teórico, é possível sustentar a ideia de que a sintomatologia - ao menos local - está desestabilizada, como se a

modalidade de saber. O que interessa, portanto, é observar como cada pessoa vive e lida com a pandemia em seu cotidiano a partir de diferentes práticas (ao falar em práticas estou me inserindo nas abordagens que se desenvolveram no interior dos Science and Technology Studies das décadas de 1970 (CF. KNOR-CETINA, 1983)).

${ }^{4}$ Conforme o último censo do IBGE. Fonte: Instituto Brasileiro de Geografia e Estatística. Disponível em: https://cidades.ibge.gov.br/brasil/pe/olinda/panorama. Acesso: 25 de agosto de 2020. Já os dados para o bairro podem ser encontrados no SIDRA (Sistema IBGE de Recuperação Automática). Disponível em: https://sidra.ibge.gov.br/Tabela/202\#resultado. Acesso: 25 de agosto de 2020. Lembrando que são dados do último censo. O censo de 2020 foi adiado para 2021, conforme site. 
Rev. Interd. em Cult. e Soc. (RICS), São Luís, v. 6, n. 2, p. 156-173, jul./dez. 2020

ISSN eletrônico: $2447-6498$

própria realidade, sob a pandemia, estivesse "instável”, cheia de incertezas sobre tempo, sobre o futuro, sobre a doença e sobre os próprios corpos.

Para dialogar com a antropologia de epidemias, e a partir de uma coleta de dados online, articularei uma aproximação com o conceito de experiência utilizado por William James (1979), principalmente como ele foi manejado por meio da antropologia "dos modernos" de Bruno Latour (2019[2012]). Nas páginas seguintes, trarei quatro casos em que o tema da suspeita de ter sido contaminado pela Covid-19 apareceu nas interações no campo de pesquisa. O resultado esperado é demonstrar que, diante da Covid-19, existe um processo de emergência de um novo arranjo social em que os agentes assimilam o novo microorganismo em seu ambiente; ao mesmo tempo em que essa reconfiguração produz tanto novas associações (LATOUR, 2012[2005]), quanto deixa desestabilizada a sintomatologia de certas doenças fora das instituições científicas e da saúde.

\section{OURO PRETO - UM BAIRRO DE “CLASSE MÉDIA"}

O bairro de Ouro Preto, em Olinda, é bastante acidentado, com morros e ladeiras, tendo uma altitude privilegiada. O que pode se comprovar devido ao grande número de antenas e torres de emissoras de televisão encontradas no bairro ${ }^{5}$. As avenidas principais de entrada e saída do bairro levam até a rodovia PE-15, que se liga com a rodovia federal BR101. O bairro fica entre os municípios de Recife (sul) e Paulista (norte). As avenidas principais são asfaltadas e o restante do sistema viário é, normalmente, pavimentado, porém, conforme nos afastamos de tais avenidas, o pavimento nem sempre é encontrado. Seus equipamentos públicos, como praças e quadras esportivas são disputados em épocas de campanha por candidatos devido, é claro, a suas condições, via de regra, sem manutenção e consertos, precisando periodicamente de reparos ${ }^{6}$. O mesmo vale para as ruas, travessas e becos de áreas que foram, historicamente, e continuam sendo, alvo de ocupações “irregulares”. Uma pequena área do bairro é chamada de Zona Rural. Entretanto, o restante do bairro é totalmente urbanizado. Seu sistema de esgoto é precário em muitas áreas, com canais e córregos abertos, sem equipamento público adequado ${ }^{7}$.

\footnotetext{
${ }^{5}$ Um de seus morros, o Morro do Peludo, foi o lar da emissora de TV Rede Globo-Nordeste até recentemente. No mesmo morro, também se encontra o Santuário da Mãe Rainha, que chega aos seus 28 anos em 2020. Fonte: https://www.folhape.com.br/noticias/santuario-da-mae-rainha-em-ouro-preto-celebra-26-anos/84242/. Acesso: 27 de setembro de 2020.

${ }^{6}$ Essa relação entre espaços públicos (e também digitais), bem como entre a Covid-19 e o período eleitoral faz parte de outro recorte da mesma pesquisa da qual este artigo se originou.

7 A questão da divisão do bairro por áreas é curiosa do ponto de vista etnográfico. O bairro se subdivide "popularmente" em: Argentina, Jatobá I, Jatobá II, Cohab/Embrião e Zona Rural. O que é interessante é que essa escala é mais complexa, pois uma interlocutora, por exemplo, adiciona à Cohab/Embrião, a Vila Manchete, a
} 
Rev. Interd. em Cult. e Soc. (RICS), São Luís, v. 6, n. 2, p. 156-173, jul./dez. 2020

ISSN eletrônico: $2447-6498$

No quesito histórico, o bairro de Ouro Preto foi oficialmente inaugurado em 1966. De lá para cá são $54 \operatorname{anos}^{8}$. A cidade de Olinda, contudo, foi fundada em $1535^{9}$. A Rede Globo uma das principais emissoras de TV e, agora, Streaming, do Brasil, - tem uma narrativa interessante sobre o assunto ${ }^{10}$. Para a emissora, conforme trabalhos jornalísticos, ela surgiu juntos aos bairros de Ouro Preto e seu vizinho, o bairro de Cidade Tabajara ${ }^{11}$. Atualmente, Ouro Preto é considerado oficialmente como um bairro de classe média ${ }^{12}$, apesar de, empiricamente podermos falar de uma realidade complexa, com áreas bastante carentes. Essa desigualdade pode ser demonstrada pelos dados de pesquisa. Gabriela, interlocutora de minha pesquisa, disse-me, em certa ocasião, o seguinte:

Ela: Aquele [grupo]do Ouro Preto Solidário/Eu entrei em contato com eles outro dia. Tava a uns meses com um monte de roupa sapato e brinquedos sem saber pra quem dar. Foram ótimos e vieram buscar! [sinal de indicador e anular cruzados]... Pessoal aqui do lado precisando e ninguém sabe..." Eu perguntei: Onde?[...] Ela: Falo em Ouro Preto/ No geral. (Fala de Gabriela, em Ouro Preto (PE). Coletado via Instagram, 24/05/2020. Grifos meus).

Outra interlocutora, que chamarei de Yara, do Coletivo Ouro Preto e que atuou desde o início com a campanha Ouro Preto Solidário, contou-me sobre como chegar nessas áreas que Gabriela disse serem "aqui do lado", referindo-se à vizinhança.

[...]Tem pessoas no nosso bairro que vivem super bem. Tem outras que não tem o que comer, mas finge que tá bem; e tem outras que realmente tão passando fome, no nosso lado, e não estamos vendo, sabe? E isso acaba comigo. Eu entrei em lugares, assim, que a pessoa não tinha fogão, não tinha geladeira, não tinha nada! Não tinha nem farinha no... no armário. E eu

Vila do "Meio", o Buracão e outras subdivisões em áreas que às vezes são classificadas por moradores/as dessas localidades. No entanto, os boletins epidemiológicos da Prefeitura de Olinda dividem o bairro em dois: Ouro Preto e 7RO. O nome 7RO (Sétimo Regimento, Olinda) vem de um quartel do exército que se localiza entre a Cohab/Embrião e o Argentina, às margens da Rodovia. Ou seja: as estatísticas sobre Covid-19 são distribuídas para o 7RO e para o restante de Ouro Preto (o que é curioso). Fontes: site da Prefeitura e do NE10. Disponível em: https://ne10.uol.com.br/canal/noticias/grande-recife/noticia/2017/02/01/violencia-toma-conta-das-ruas-deouro-preto-e-amedronta-moradores-660046.php; e https://www.olinda.pe.gov.br/. Acesso: 27 set. 2020.

${ }^{8}$ Fonte: Hemeroteca Digital.

${ }^{9}$ Fonte: site da prefeitura de Olinda.

${ }^{10}$ Fonte: g1.globo.com. Disponível em: http://g1.globo.com/pernambuco/noticia/2012/04/bairros-de-olindasurgiram-junto-com-globo-nordeste.html. Acesso: 1 set. 2020.

${ }^{11}$ Tabajara é uma etnia indígena que não existe mais em Pernambuco, mas que foi, junto aos Potiguara, etnias que se aliaram à colônia portuguesa como alternativa de sobrevivência e que, ao menos até 1733, representavam as lideranças e governos indígenas em alianças com a Coroa (Cf. SILVA, 2007). Atualmente, as etnias indígenas encontradas, oficialmente, em Pernambuco são: Atikum, Fulniô, Kambinawá, Kapinawá, Pankará, Pankararu, Popipã, Truká, Tuxá e Xucurú. Fonte: NEPE - Núcleo de Estudos e Pesquisas sobre Etnicidade. Disponível em: https://www.ufpe.br/nepe/povos-indigenas. Acesso: 1 set. 2020.

${ }_{12}$ No ano de 2017, foi feita uma matéria sobre assaltos no bairro de Ouro Preto, e, segundo o major responsável à época, Ouro Preto atraía assaltantes devido a localidade e ao perfil socioeconômico do bairro. Fonte: NE10. Disponível: https://ne10.uol.com.br/canal/noticias/grande-recife/noticia/2017/02/01/violencia-toma-conta-dasruas-de-ouro-preto-e-amedronta-moradores-660046.php. Acesso: 1 set. 2020. 
fiquei pensando: “caramba, como eu sou privilegiada, sabe?" E, assim, como é que eu posso chegar nessas pessoas e dizer assim, "não, você tem que pensar o seu bairro". Como é que eu posso falar com essa pessoa que tá passando fome que ela tem que, ainda, pensar no bairro dela, se ninguém tá pensando nela? [...] (Fala de Yara, Ouro Preto/PE. Transcrição de áudio de WhatsApp, 04/08/ 2020. Grifos meus).

O Coletivo Ouro Preto (COP) aparece como ponto de partida interessante para ilustrar uma parte da realidade vivida no bairro, afinal, Gabriela e Yara ajudaram pessoas em situação que dificilmente seriam as esperadas para um bairro de classe média. Neste sentido, é interessante observar que o grupo atua no bairro, mas nem todo mundo conhece sua atuação. E esta é a oportunidade para mencionar um terceiro interlocutor, mas que, no que tange os objetivos desse artigo, revelou como lidou com a suspeita de Covid-19.13

\section{3 "TÁ TODO MUNDO ESQUECENDO DAS OUTRAS DOENÇAS, COMO CHIKUNGUNYA E DENGUE"}

José - um homem de meia idade - e sua esposa, Renilda, moram em uma pequena travessa do bairro de Ouro Preto, por trás de uma pequena mercearia. A área onde José mora fica próxima a um "canal" (que faz parte do Riacho Ouro Preto e que cruza o bairro, a mais ou menos uma quadra de distância $\left.{ }^{14}\right)$. A rua onde ele mora não é totalmente pavimentada. Seu José faz serviços de pedreiro, eletricista e encanador. Conheci-o antes da pandemia. Certo dia, fiz uma ligação telefônica para saber se ele estava bem e trabalhando. Já era 1 de julho e, portanto, estávamos em um momento em que o "afrouxamento" das medidas sanitárias já estava ocorrendo ${ }^{15}$. Para minha triste surpresa, José estava doente. Ele apresentava os seguintes sintomas: dores no corpo e nas articulações, tosse, perda de paladar e olfato, febre, "de cama" ${ }^{16}$, catarro e secreção ${ }^{17}$. Apesar dos sintomas, ele me disse que não era Covid-19, mas me pareceu em dúvida.

Seis dias depois, seu José foi à minha casa. Estava de máscara. Se sentia melhor. Convenci-o a retornar com mais sete dias depois, mas adiantei o pagamento, já que o

\footnotetext{
${ }^{13}$ Tentei fazer uma intermediação para que o Coletivo Ouro Preto auxiliasse o José, mas descobri que a rede em que o COP atua era desconhecida para o seu José, que não dispõe de telefonia móvel que opere com tecnologia $3 \mathrm{~g}$ ou $4 \mathrm{~g}$. Neste caso, José se encontra nesse lugar em que as ações em rede não chegam. Meu papel foi tentar conectá-lo a essa rede como uma devolutiva antropológica. Felizmente, conseguimos doações depois de algum tempo e, segundo: a situação de José e sua esposa melhorou financeiramente.

${ }^{14} \mathrm{O}$ Riacho Ouro Preto faz parte da Bacia Hidrográfica do Rio Paratibe e é um canal afluente do Rio Fragoso (Cf. COSTA et al. 2016). Ambos importantes rios da região.

${ }^{15} \mathrm{O}$ lockdown de Pernambuco ocorreu entre os dias 15 e 31 de maio.

${ }^{16}$ É comum utilizar essa expressão, localmente, para descrever um estado de saúde grave, necessitando ficar deitado e de repouso. Há outros relatos sobre esse termo em minha pesquisa.

${ }^{17}$ Reuni esses sintomas dentro da categoria sintomatologia.
} 
Rev. Interd. em Cult. e Soc. (RICS), São Luís, v. 6, n. 2, p. 156-173, jul./dez. 2020

ISSN eletrônico: $2447-6498$

perguntei como estava a situação e ele assumiu que estava difícil diante da Covid-19, pois chegou a perder serviço porque adoeceu. Foi, inclusive, por isso que entrei em contato com o COP no intuito de ajudá-lo.

Mais alguns dias depois, finalmente, José apareceu, junto à Renilda - que sempre o acompanha e o auxilia em seus serviços -, e, na ocasião, conseguimos resolver outro problema de encanação em minha casa. Mas, no quesito sintomatologia, algo chamou a atenção. Seu José havia “descoberto" qual era a causa para seu adoecimento anterior. Segundo ele, era Chikungunya. Perguntei-o como ele descobriu e ele me disse que devido à "Covid" tá todo mundo esquecendo das outras doenças, como essa e a Dengue ${ }^{18}$.

José não recorreu a um hospital ou clínica, como uma Unidade de Pronto Atendimento (UPA), Posto de Saúde da Família (PSF), nem foi a nenhum outro hospital local, como os chamados "hospitais de campanha", especializados em lidar com suspeita de Covid-19 ${ }^{19}$. Ele simplesmente avaliou seus sintomas, comparou o que eu havia dito com o que um atendente de uma farmácia o disse e... confiou no diagnóstico (ou, simplesmente, foi o que decidiu me dizer). Se esse caso pode deixar alguma dúvida quanto à confiabilidade, vejamos, a seguir, um caso "indireto", no qual não havia nenhuma negociação entre mim e o interlocutor. Mas antes, é importante "seguir" José. Ele manifestou certos sintomas comuns à Covid-19, principalmente cansaço e perda temporária de olfato e paladar, entre outros. Depois de ficar de repouso em casa, e tendo perdido ao menos um serviço (trabalho), foi até uma farmácia local. Alguém de lá deu-lhe um diagnóstico sem nenhum exame clínico ou de laboratório. Alguns dias depois José já estava trabalhando, apenas com secreções e certa tosse.

\section{EXAMES CLÍNICOS: "SEI QUE DANADO FOI AQUILO NÃO”}

Diferente de José e Renilda, que não fizeram parte do recorte inicial de pesquisa, surgindo alguns meses depois do início da pandemia, a Daniela, e sua família, aceitaram participar da pesquisa desde o início. A família de Daniela (nome fictício) é composta por ela, dois filhos (menores de idade) e seu marido. Ela tem quarenta e três anos e ele trinta e seis. Em um questionário ${ }^{20}$ respondido por Daniela, ela se declarou como uma mulher negra e desempregada não procurando emprego. A renda de sua família, que mora em casa alugada, é

\footnotetext{
${ }^{18}$ Registro feito no dia 21 de julho de 2020.

${ }^{19}$ No bairro de Ouro Preto, existe uma Policlínica do Sistema Único de Saúde (SUS). Além disso, existe, até onde sei, ao menos dois Postos de Saúde da Família: um na área denominada Argentina, próximo ao quartel militar e outro na Cohab (7RO). Neste caso, como se verá, o Sr. José não foi a nenhuma destas clínicas.

${ }^{20}$ Questionário elaborado e aplicado à distância com a plataforma SurveyMonkey. Metodologicamente foi útil experimentar essa ferramenta online para resolver o desconforto de perguntar a pessoas conhecidas diretamente sobre suas respectivas rendas mensais.
} 
Rev. Interd. em Cult. e Soc. (RICS), São Luís, v. 6, n. 2, p. 156-173, jul./dez. 2020

ISSN eletrônico: $2447-6498$

de $\mathrm{R} \$ 521,00$ a $\mathrm{R} \$ 780,00^{21}$. Tal renda é proveniente do trabalho de seu marido. Daniel trabalha como motorista de aplicativo e, inclusive, precisou passar cinco dias do mês de maio (2020) na casa de uma parente, pois suspeitava ter contraído a Covid-19. Depois de ter sido atendido em uma UPA que se encontra em um bairro vizinho ao de Ouro Preto, neste caso, no bairro de Cidade Tabajara, foi para a casa da mãe. O caso foi resolvido alguns dias depois. Vejamos como Daniela relata o assunto, depois de ter dito que aplicou três injeções nele:

Semana passada foi pank/[Daniel]foi parar na upa com fortes dores na coluna/Depois passou 5 dias na casa da mãe pois ficamos com cuidado em Júlia [Filha] e Marcos [Filho] (Fala de Daniela, Ouro Preto/PE. Registro textual de mensagem de WhatsApp do dia 26/05/2020).

“mas agora [Daniel] tá melhor, graças a Deus. Já voltou a trabalhar... Tá bem melhor...foi um susto danado! Até de muleta [ele] ficou andando. Sei que danado foi aquilo, não. Mas disseram que foi inflamação no nervo ciático [tom irônico, de deboche]. Mas graça a Deus melhorou". (Fala de Daniela, Olinda/PE. Transcrição de áudio de WhatsApp. Registro do dia 26/05/2020).

Por que a ironia e o aparente ceticismo quanto ao diagnóstico? Vejamos como ela lida não com um humano, mas com uma inteligência artificial em relação a uma pergunta feita por seu marido a respeito, novamente, de questões de "saúde":

- "Amor, posso tomar uma cervejinha esse final de semana?" - Fala Daniela, imitando o tom de voz usado pelo marido.

- Claro que não! - Diz Daniela.

- “Oxe ${ }^{22}$, por que não, já completou 24h?" - Continua ela, imitando o marido de novo. - Eu disse, "pode não menino, verifica aí no Google quanto tempo depois dessa injeção [se] pode beber". Ele verificou. - Agora a voz começa a se tornar risonha, como alguém que ri antes do fim de uma piada. Ela ri antes de continuar. - "O Google falou que só depois de quinze dias." - Disse ela, como se fosse o marido respondendo. - Aí ele botou 'na voz', "Google [vai] se lascar" - E ela, Daniela, começou a rir novamente. - Arretado. Mas foi uma boa melhora. - Explicou ${ }^{23}$. (Fala de Daniela, Ouro Preto/PE. Registro do dia 26/05/2020).

É possível notar, no geral, a importância do Google na interação entre ela, seu marido e a injeção (antibióticos) que o marido tomou, bem como notar uma alteração temporal, também, pois dela resulta a ideia de que houve interferência no hábito de "tomar uma

\footnotetext{
${ }^{21}$ Esse valor fica abaixo de um salário mínimo no Brasil. Dividido pelo número de pessoas na cada de Daniela, sua condição de renda a coloca em uma classificação oficial de "baixa renda".

22 "Oxe" é uma interjeição regional bastante comum que, aqui, expressa frustração.

23 "A voz" é o recurso de acessibilidade do Google e que vem pré-instalado em alguns aparelhos de celular. Assim, você faz uma pergunta e uma inteligência artificial, voz feminina, responde. Neste sentido, houve uma "mediação" sociotécnica (LATOUR, 2000; 2001) realizada pela inteligência artificial: a decisão, na interação, veio depois que a IA respondeu à pergunta de Daniel. O segundo aspecto a ser destacado é o semântico. O uso de "arretado", aqui, é o mesmo que "irritado".
} 
Rev. Interd. em Cult. e Soc. (RICS), São Luís, v. 6, n. 2, p. 156-173, jul./dez. 2020

ISSN eletrônico: 2447-6498

cervejinha no fim de semana”. Muito diferente de José, Daniela desconfiou de uma "autoridade"; neste caso, uma enfermeira que diagnosticara seu marido; mas não duvidou, na ocasião, do Google.

Essa atuação do digital no físico é o que tem levado à superação, em etnografia online, da separação rígida entre ambientes virtuais e ambientes online (LEITÃO; GOMES, 2017). Há quase vinte anos que tal separação está sendo abolida (MILLER, 2004), mas isso não significa, por outro lado, que não seja possível prosseguir com pesquisas que se concentram apenas no "campo virtual". A questão é compreender como esse virtual influencia o "real", como no caso de campanhas feitas via redes sociais (CESARINO, 2019; 2020a; 2020b). No caso de Daniela, a questão é apenas pontual, da presença da mediação não humana, da participação (agência) de uma inteligência artificial, um robô, que responde a um comando de voz por meio de um dispositivo eletrônico. Para autores que lidam com o tema da agência sociotécnica (LATOUR, 2001) ou que se alinham com a ideia que os objetos são agentes caso seja levado em consideração que a interação entre uma pessoa e um objeto possibilita um efeito ou consequência prática que, de outro modo, não seria possível (LATOUR, 2001; GELL, 2018[1998]), a agência dos objetos é coprodutora da ação. Aqui, ela aparece como uma mediadora cujo efeito observável sobre a interação se apresentou como um complemento ao saber medicinal manejado por Daniela em relação ao seu marido e ao diagnóstico clínico dele. Portanto, o efeito ou consequência da interação entre os agentes foi a medicalização de Daniel, de um lado, e seguir as recomendações do robô quanto ao não consumo de álcool, de outro.

Um segundo aspecto que é preciso pontuar é sobre a afinidade pragmática dos argumentos sobre agência, acima. Latour (2019), mas antes dele William James (1979) dentre outros pragmatistas anglo-americanos/as - se concentraram não necessariamente nos conceitos, na "razão" ou na "verdade", mas sim nas consequências ou efeitos do uso de tais conceitos. ${ }^{24}$ Tais efeitos podem ser entendidos como resultado da agência. Mas é preciso notar o aspecto da "experiência pura" (JAMES, 1979) para compreender melhor as interações e tais efeitos delas decorrentes. Para James, a "experiência pura" é um recurso metodológico que se aplica ao momento não refletido de algum acontecimento sofrido por alguém. Portanto, a cada passo, uma pessoa pode estar processando uma experiência pura como ter suspeita de ter se contaminado com a Covid-19, por exemplo. No caso do antropólogo, cabe manejar estas experiências e a produção de sentido sobre elas, para compreensão dos efeitos que esta

${ }^{24}$ Ver em James, principalmente, "Ensaios de empirismo radical", "Um mundo de experiência pura" (1979[ 1943]). 
Rev. Interd. em Cult. e Soc. (RICS), São Luís, v. 6, n. 2, p. 156-173, jul./dez. 2020

ISSN eletrônico: $2447-6498$

situação gera. No caso de José e Daniela, ou de seu marido, a experiência pura seria, analiticamente, correspondente ao momento da suspeita. Assim, a relação entre suspeita e a interação são, por conseguinte, o momento da produção de um sentido/diagnóstico sobre outros. A agência, portanto, está tanto no elemento corpo/sintomas, como na ação corpo/interações e, daí, seus efeitos. Em outras palavras, a ação ocorre e nós, analistas, recortamos os momentos que serão descritos por etapas.

Neste sentido, a agência pode ser encarada a partir das interações entre os seres vivos, não vivos e até inanimados (como pregos, ferramentas etc.) que participam de uma ação observada. Em suma: ao compreender o papel da agência destes seres (I.A. Google. Celular.), observa-se uma consequência prática muito específica: os saberes estão sendo conectados. No exemplo da Daniela, a internet atua como conector entre a pergunta de Daniel ("Amor, posso tomar uma cervejinha esse final de semana?”), o Google e a resposta dela (“pode não menino, verifica aí no Google quanto tempo depois dessa injeção [se] pode beber”).

O destaque dado à agência não humana, acima, é útil para refletir sobre a rede, digamos, da transmissão do saber oral, tal como ocorreu no caso de José. Recapitulemos: José não apenas evitou ir a um hospital para acessar serviços de saúde, como também não participa da rede sociotécnica (LATOUR, 2012) acionada por internet via celulares e computadores. Sua escolha foi se deslocar fisicamente de sua casa até uma farmácia na vizinhança, na qual um farmacêutico o diagnosticou. Já suspeita de Daniela foi, mesmo sob ceticismo, sanada por uma enfermeira. Portanto, neste caso, não era Covid-19. No caso de José, também (supostamente) não. Ao deslocarmos a atenção para a relação entre práticas e agência, tornase possível identificar como os agentes constroem alternativas diante das experiências vivenciadas. Vejamos, agora, um terceiro caso.

\section{5 "TIVE MEDO, VISSE"}

Renam é um homem de aproximadamente trinta anos. Casado, pai de uma criança menor de 5 anos. Mora em um imóvel próprio, com dois quartos, cozinha, banheiro e garagem. Ele é professor da rede estadual de Educação, passou recentemente em um concurso público, mas antes já era concursado e atuava na administração municipal de Olinda. Diferente de José ou de Daniela, Renam cursou e concluiu a Educação Superior, uma licenciatura. A renda mensal na sua casa é, atualmente, superior a dois salários mínimos por 
Rev. Interd. em Cult. e Soc. (RICS), São Luís, v. 6, n. 2, p. 156-173, jul./dez. 2020

ISSN eletrônico: $2447-6498$

pessoa. Se falei que o bairro de Ouro Preto era considerado de classe média, mesmo que baixa, Renam com certeza se enquadraria nessa faixa ${ }^{25}$.

$\mathrm{Eu}$ - Ei, rapaz, vê... tu disse que conhecia alguém que pegou Covid-19, não foi?

Renam - minha tia/E minha madrasta.

$\mathrm{Eu}$ - Eita, rapaz!/Ela ainda tá ou se curou?

Renam - Curou/Já estão trabalhando faz tempo/Foi em abril

Eu - Ela foi diagnosticada mesmo, né? Não foi tipo "autodiagnóstico" né?/Não é duvidando/mas é importante, pra mim, saber

Renam - Minha tia trabalha em Hospital [,] fez o teste lá

$\mathrm{Eu}$ - hummm/entendi

Renam - E minha madrasta tb fez o teste

Que bom, né, véi/q tudo deu certo

Renam - Então/Só de minha vó não ter pego

$\mathrm{Eu}$ - verdade...

$\mathrm{R}$ - Eu acho que tive por causa disso/Pq foi praticamente no mesmo dia que os sintomas apareceram, mas no meu caso foi bem leve. Só dor de cabeça e não fiz exame.

$\mathrm{E}$ - entendi/Muita gente pensa que teve/E muita q não teve/kkk

$\mathrm{R}$ - Tive contato proximo, por isso que desconfio/dormi na sala uns dias e evitei contato com meu filho e minha esposa/Tive medo visse./Fiquei colocando soro no nariz [,] era a única coisa que aliviava

E - aliviava o q?/ a dor de cabeça?/pq tu só falou de dor de cabeça

$\mathrm{R}$ - a respiração ficou dificultada tb, por uns 3 dias. (Fala de Renam, Ouro Preto/PE, por mensagem de WhatsApp. Registro do dia 27/07/2020. Grifos meus).

Renam estabeleceu uma correlação temporal interessante: ele disse que os sintomas começaram a aparecer "praticamente no mesmo dia" em que apareceram os sintomas nas suas parentes. Segundo: ele disse que teve contato “próximo". Se José confiou no autoridade de um atendente em uma farmácia que o diagnosticara com Chikungunya; e se Daniela, resignada, aceitou que não era Covid-19 o caso de seu marido devido à autoridade de uma enfermeira; Renam estabeleceu critérios lógico-dedutivos próprios, mas com base, também, em seus sintomas (falta de ar e dor de cabeça). Com base nisso, ele tomou precauções (evitou contato com o filho e a esposa) e também fez um tratamento para lidar com a falta de ar, ministrando soro no nariz.

Poderíamos dizer, aqui, que o saber está contido no próprio corpo do agente? Seu julgamento crítico comparou os sintomas com o momento em que teve contato com suas parentes e chegou à conclusão de que foi contaminado. Ora, se teve contato com elas e os

\footnotetext{
${ }^{25}$ Na classificação do IBGE conforme Plano de Orçamento Familiar do período e 2017-2018, as classificações são 7, da mais baixa (até R\$ 1908,00), e inclui "sem rendimento", a mais alta (mais de R\$ 23,850). Renam se encontra no nível 3, com rendimentos de 3 a 6 salários mínimos. É importante mencionar que esses valores em reais são equivalentes em salários mínimos ao ano de 2012. Todavia, creio que a divisão nessas faixas é, ainda, apropriada.
} 
Rev. Interd. em Cult. e Soc. (RICS), São Luís, v. 6, n. 2, p. 156-173, jul./dez. 2020

ISSN eletrônico: $2447-6498$

exames delas deram positivo para Covid-19, então seus sintomas, segundo ele, eram resultado do contato.

Deveríamos concordar com Renam? Peremptoriamente: não. Cientificamente falando, há outras inúmeras variáveis para serem levadas em consideração: poderia ser outra doença (ver José e a Farmácia); poderia ter sido qualquer outra coisa (ver Daniela e seu descrédito "sei que danado foi aquilo não"); poderia, indago, ser psicológico ("Tive medo visse")? De todo modo, não cabe à abordagem antropológica aqui advogada uma oposição "científica" em detrimento das experiências e saberes apresentados; mas sim levar a sério a experiência do Renam.

Em outras palavras: Renam tem seu corpo conectado com o que que está circulando sobre Covid-19 pelos ambientes. Se eu discordo dele, isso não significa que eu esteja certo e ele errado; significa que ele atualizou o "contexto" sobre a Covid-19 ao seu corpo e aos seus sintomas, tornando-se doente, pois possivelmente contaminado pela Covid-19; enquanto eu "contextualizo" seu discurso em um enunciado que dá primazia a um saber-poder estabilizado (a clínica, o laboratório, a episteme), mas que circula em uma rede específica que tenta estabilizar a sintomatologia da Covid-19. Contudo, o que acontece quando outras práticas estão competindo para definir quais saberes são mais adequados para lidar com os corpos no momento bio ou microbiopolítico (PAXSON, 2008) fora dos laboratórios e de suas redes?

Para refletir sobre essa relação entre o ambiente, o individual e o controle político, é interessante dialogar com a noção de microbiopolítica. Paxson (2008) realizou uma etnografia cujo objeto era compreender a relação entre micro-organismos presentes em queijos, o comércio desses produtos, a vigilância sanitária e o ativismo "pós-pasteuriano" ligado ao assunto. Para a autora (PAXSON, 2008), a ideia de uma microbiopolítica se une (is joined) à tese da biopolítica foucaultiana sobre o controle da vida e dos corpos com o uso da estatística como meio de se fazer políticas. Nessa "união", a "pasteurização" seria parte do fenômeno descrito por Latour (PAXSON, 2008), segundo o qual os micro-organismos, não apenas as pessoas, participam da "cultura" e da "sociedade" 26.

No entanto, Paxson, (id.) diz que vivemos um momento pós-pasteurização na medida em que, atualmente, existem movimentos ativistas que estão se engajando em propor alianças com micro-organismos, ao invés de manterem uma lógica sanitarista e higienista. No caso da Covid-19, os casos até aqui apresentados parecem demonstrar uma relação com o microorganismo e com as normas de controle sanitário ainda complexas. Lembrando das falas até

\footnotetext{
${ }^{26}$ Emprego cultura e sociedade em sentido lato, não epistêmico. Tal como se usa em sentido comum.
} 
Rev. Interd. em Cult. e Soc. (RICS), São Luís, v. 6, n. 2, p. 156-173, jul./dez. 2020

ISSN eletrônico: $2447-6498$

agora apresentadas, a relação com políticas sanitaristas e higienistas não são uniformemente distribuídas. O que parece semelhante ao caso de Paxson (2008) é a ideia de que a microbiopolítica diante da pandemia reconfigura nossas relações com esses seres invisíveis "a olho nu", dando visibilidade a certos micro-organismos em detrimento de outros. Ao se tornar "mais visível", as suspeitas sintomatológicas visibilizam a Covd-19, dando primazia ao novo Corona vírus. O que acontece, no entanto, quando não há suspeitas? Vejamos, a seguir, um quarto e último caso.

\section{6 "EXISTEM AS PESSOAS QUE SÃO ASSINTOMÁTICAS"}

Eu perguntei à Isaura, uma artista plástica, artesã, cozinheira de comidas veganas, autônoma, se ela havia suspeitado de ter contraído a Covid-19 nos últimos meses (até o mês de agosto, neste caso). E ela respondeu:

\footnotetext{
Meu querido, falando sobre a Covid: eu acredito que não tive. E nem ninguém lá em casa. Mas, assim, existem as pessoas que são assintomáticas (né?). Porque eu saí. Eu me expus (né?). Eu ia no mercado, ia no médico (vou né?). Então, assim, eu não posso afirmar com certeza que eu não tive, mas eu acredito que não.

Pelo menos não tive nenhum sintoma.

$\mathrm{E}$, na verdade, eu ainda estou, de certa forma, fazendo a minha quarentena (né?). Eu não tô indo pra aglomerações... lugares assim, né... festinha, essas coisas. Nada. Eu continuo, assim, em casa. Mas saindo pra resolver minhas coisas normalmente (Fala de Isaura, Ouro Preto/PE. Transcrição de áudio de WhatsApp. Dia 25/08/ 2020).
}

Se, até agora, eu demonstrei casos possíveis de Covi-19, talvez à exceção do marido de Daniela, o Daniel, cujo diagnóstico apontou para um problema outro, não foi sem intenção de situar os saberes em ambientes. A sintomato-logia só opera em redes. Nas redes dos chamados "casos confirmados" e "óbitos", são os números como representação que se institucionalizam, como agentes estatísticos, sedimentando o que é fato e o que é opinião. Num estudo recente sobre a Covid-19, o risco de transmissão por pessoas assintomáticas estava associado a pessoas "pré-sintomáticas". Ou seja: existem pessoas que foram contaminadas, mas já podiam transmitir a doença mesmo antes de manifestarem os sintomas da doença (GHANDI et al, 2020, p. 2). Tal estudo, feito em laboratório e publicado em uma rede sociotécnica (LATOUR, 2012), isto é: em um periódico inglês, lida com o mesmo discurso que a minha interlocutora, a Isaura, lidou. No entanto, a documentação do saber biomédico compara provas e evidências em um tipo de economia das experiências ou cadeias de referências que podem ser rastreadas em rede (LATOUR, 2019) e cujos ambientes são 
intercambiadores de informação. Como destaca Latour (2012), estas informações não apenas “comunicam" ações no pretérito, elas afetam ações futuras.

Isaura demonstrou ter uma informação que saía dos laboratórios, vinda de outros ambientes. Não que se trate exatamente do mesmo artigo ora mencionado (GHANDI et al, 2000), mas se entendemos o termo "assintomático" como uma palavra cujo sentido incorporado não deve ser presumido, mas observado em movimento, passando de um suporte material a outro ${ }^{27}$, então isso significa que suas transformações podem ser analisadas e $\operatorname{comparadas}^{28}$. Na rede sociotécnica (LATOUR, 2012), entre periódicos, o que é fato e o que não é, precisa se estabilizar. É preciso haver consenso para que a circulação seja legitimada e, daí, transportada para fora dos laboratórios. É certo que isso acontece de maneiras apressadas, em certas circunstâncias, como no caso da suspeita de que durante a epidemia de Zika vírus em Pernambuco, poderia haver correlação entre o vírus e os mosquitos comuns (do gênero Culex $)^{29}$. Ainda assim, são necessários agentes fazendo essa informação se espalhar pela paisagem. Porém, o fato só se mantém firme e estável continuamente quando dentro de redes sociotécnicas (LATOR, 2012); quando não, ele pode não resistir ao julgamento de um agente. Não porque seja fato ou mito, mas porque ao cruzar o caminho da experiência vivenciada pelas pessoas; elas parecem, e podem, ignorar ou deliberadamente não seguirem o que esses fatos sugerem. Algo que, aliás, já foi demonstrado por Paxson (2008) em relação ao debate liberdade individual versus proteção estatal.

Mais ainda: o que dizer quando a experiência não se traduz em números? O que dizer da experiência de sintomas que foi curada na farmácia sem ir a um hospital (José); da suspeita que não foi estatisticamente confirmada (Daniel); dos sintomas equiparados que duplicaram um diagnóstico clínico sem tornar-se estatística (Renam); ou, ainda, dos casos assintomáticos (Isaura)? Categoricamente: ao não virar estatística, não se tem como resultado a mobilização de práticas político-estatais. Não se trata, por outro lado, de superestimar a estatística, mas sim de demonstrar que ela participa de certas políticas públicas e de artigos científicos, tornando-se uma ciência sancionada, confiável e legítima nos ambientes em que opera.

\footnotetext{
${ }^{27}$ Indico, aqui, o livro que gerou a etiqueta "virada ontológica" na antropologia "thinking through things (AMIRA; HOLBRAAD; WASTELL, 2007). Como se sabe, Latour é um dos principais nomes por trás da virada ontológica devido a essa atenção aos elementos que agem junto com as pessoas e mobilizam a ação, levando-a adiante. Neste sentido, a própria ideia de conceito pode significar uma materialidade (Cf. também sobre a relação materialidade e linguagem Latour (2019); e Viveiros de Castro (2014)), pois - por exemplo - o transporte de uma ideia para pessoas por meio de um carro de som da prefeitura (diário de campo: 10/07/2020), ou ainda em um smartphone conectado à internet, continua exercendo um efeito sobre o ambiente. Portanto, exerce uma ação "material" ou, preferimos, uma mudança efetiva (effectiveness) sobre a paisagem.

${ }^{28}$ Estou utilizando o modo de existência das preposições de Latour (2019). Isto é: entendendo que a palavra circula e seu sentido é que precisa ser apreendido conforme interlocutores/as a utilizam.

${ }^{29}$ Ver. Scott et al (2020); e, mais especificamente, BRITO, Gabriel F. de (2020).
} 
Rev. Interd. em Cult. e Soc. (RICS), São Luís, v. 6, n. 2, p. 156-173, jul./dez. 2020

ISSN eletrônico: 2447-6498

No início da pandemia, no mês de março, foi lançado um decreto municipal no dia 30 daquele mês. Naquele mesmo dia, a cidade tinha a taxa de 5 casos confirmados, 70 descartados, 10 em investigação e 5 inconclusivos (total de 90 notificações) ${ }^{30}$. Era um decreto de calamidade pública que, entre outras prerrogativas, autorizava o então prefeito Lupércio Carlos do Nascimento (Partido Solidariedade), enquanto chefe do executivo, à abertura de créditos extraordinários para lidar com os impactos da Covid-19 ${ }^{31}$. Contar a realidade de adoecimentos e fazer seu registro é o que estabelece uma circulação de provas e evidências. $\mathrm{Na}$ medida em que os casos começaram a ser contados, rapidamente foi decretado estado de calamidade pública. Dito de outra maneira: a política entra em ação em conexão com a área da saúde, produtora dos números a partir de um aparato institucional cuja rede opera dentro de um saber autorizado. É essa relação deveras chamada de biopoder (Cf. PRAXON, 2008) que está operante. É ela, portanto, que transforma a Covid-19 em números, localmente, manejando a informação por meio do critério de visibilização numérica do vírus.

Metafisicamente falando, no entanto, ocorre um acesso ao "invisível reino microbiológico" por meio de duas ciências que compartimentam o modo como percebemos a realidade, sendo uma ciência responsável por dar visibilidade ao vírus nos corpos (saúde); e outra visibilizar o comportamento do vírus em contato com as pessoas em ambientes fora do laboratório (a estatística). Desse modo, outras instituições estabelecem as normas de convivência com o reino invisível (o Estado). Forma-se, finalmente, a rede sociotécnica que mobiliza a "política-ciência" dos corpos. Se os números, contudo, são eficientes para fazer valer as normas, já não é a ocasião para discutir o assunto. Mas minha hipótese é de que, atualmente, tanto ciência quanto a estatística, isoladamente, vivem uma crise de credibilidade "sintomática" e que aponta para uma reconfiguração de suas respectivas (im)pertinências institucionais (ao menos nos ambientes que fazem parte do campo de pesquisa do qual este artigo se originou).

\section{CONSIDERAÇÕES FINAIS}

O que podemos concluir com esses casos é que as decisões tomadas apontam para uma relação entre saúde e experiencia corpórea individual como uma forma de mediação que produz um entendimento sobre os juízos acerca dos sintomas. O que é o mesmo que dizer que todo mundo até agora tem uma capacidade de "falar pela sua própria experiência"; todo

\footnotetext{
${ }^{30}$ Site da Prefeitura de Olinda: https://www.olinda.pe.gov.br/wp-content/uploads/2020/03/Boletimepidemiologico_n11_2020 30.03.20.pdf. Acesso: 27 de setembro de 2020.

31 Fonte: Diário Oficial dos Municípios do Estado de Pernambuco. Disponível em: http://www.diariomunicipal.com.br/amupe/. Acesso: de 18 agosto de 2020.
} 
Rev. Interd. em Cult. e Soc. (RICS), São Luís, v. 6, n. 2, p. 156-173, jul./dez. 2020

ISSN eletrônico: $2447-6498$

mundo parece ter algum juízo prévio que o/a capacita a tomar uma decisão inicial sobre como proceder em relação ao aparecimento dos sintomas. Todavia, diante da pandemia, é possível dizer que que a suspeita de estar contaminado por ela, ao menos até os primeiros seis meses de pandemia no Brasil, é uma constante. Notemos: a suspeita funciona como um articulador de experiências sintomáticas prévias. Em segundo lugar, decide-se por qual entendimentosaber se deve recorrer (mesmo que seja o saber prévio ou o Google).

É aqui que esta fala pela sua própria experiência não pode ser traduzida como uma abordagem (fenomenológica) na qual experiência se traduz em saberes e, por conseguinte, em fato/eficácia. Muito pelo contrário: os casos empíricos demonstram a dúvida diante da experiência. Depois, a tomada de decisão conforme outros saberes. No caso do Sr. José, o saber de um farmacêutico traduzia a experiência que ele próprio viveu; não a experiência do farmacêutico que o atendeu. Houve reflexão e diálogo para produzir uma compreensão que, independentemente de ser clínica ou laboratorialmente testada, gerou um efeito/decisão: não estar com covid-19, mas sim com Chikungunya. O que é interessante de se notar é que se José tivesse feito o exame laboratorial e testasse positivo, sua experiência e o saber manejado pelo farmacêutico simplesmente teriam sido descartados.

Já os casos de Renam e de Isaura são diferentes apenas em um primeiro momento. Ele se autodiagnosticou e concluiu que estava com Covid-19; ela, mesmo fazendo o mesmo, se considerou uma possível não contaminada, mas, ainda assim, possível assintomática. São duas experiências diferentes, mas que levam, como já dito, a, primeiro: viver uma transformação corporal (ter sintomas) que gera uma reflexão e um juízo sobre o que fazer; e segundo: a experiência de viver a suspeita, ou dúvida, leva a uma conclusão que opõe experiência como o locus privilegiado da verdade ao conjunto de contatos e informações disponível para fazer a mediação entre o que se viveu com o que outros já sabem. Afinal, essa é exatamente uma das teses de William James (1979) sobre como a experiência apreende a realidade. Ainda assim, é preciso afastar a falsa impressão de ter algum acesso ao "mecanismo" de operação da experiência e, antropologicamente, nos deslocar para coletar os efeitos pelos quais são postos em prática os componentes resultantes da experiência vivida.

Por fim, cabe dizer que não encerro a análise na experiência sintomatológica. Desdobro e cito a relação entre o que se vive e como se vive em relação ao ambiente, seja ele digital ou físico - ambos materiais. Com isso, torna-se possível sedimentar a análise dos diferentes acontecimentos. Este artigo, portanto, analisou apenas como quatro interlocutores/as da pesquisa passaram pela experiência de suspeitar de ter suspeitas de terrem sido contaminados/as pela Covid-19 ou o que acham sobre a pandemia no sentido 
Rev. Interd. em Cult. e Soc. (RICS), São Luís, v. 6, n. 2, p. 156-173, jul./dez. 2020 ISSN eletrônico: 2447-6498

sintomatológico. Foi cientificamente pertinente identificar que a Covid-19 "desestabilizou" momentaneamente o quadro sintomatológico, pois isso indica a necessidade de dar atenção a estes "cortes" ou descontinuidades das redes sintomatológicas institucionais.

Ao mesmo tempo é de se destacar que a relação saúde e estatística continua sendo uma combinação biopolítica. A problematização decorrente daí é se essa visibilização da Covid-19 por meio de representação estatística é "aceita" pela população, pois até o momento não foi posto em dúvida a existência da pandemia, mas sim a possibilidade de contágio (ao menos etnograficamente não foi registrada a negação, apenas o ceticismo, em certos casos, quanto às “estatísticas oficiais" - seja para acusá-las de "infladas" ou se "subnotificadas").

\section{REFERÊNCIAS}

AMIRA, Henare; HOLBRAAD, Martin; WASTELL, Sari. Introduction: Thinking through things. In: (Ed.) AMIRA, Henare; HOLBRAAD, Martin; WASTELL, Sari. Thinking through things: Theorizing artefacts ethnographically. London, Routledge, 2007. pp. 131.

BRITO, Gabriel F. de. In: SCOTT, Russel Perry; LIRA, Luciana; MATOS, Silvana (Orgs.). Práticas sociais no epicentro da epidemia de Zika. Recife, Editora UFPE, 2020.

CASTRO, Eduardo Viveiros de. Who is Afraid of the Ontological Wolf? Some Comments on an Ongoing Anthropological Debate. The Cambridge Journal of Anthropology, v. 33, n. 1, spring, 2015. pp. 2-17. Disponível em: https://lse.rl.talis.com/items/981E3686-7DD6-E52B0E84-5F923EB82D09.html. Acesso: 29 set 2020.

CESARINO, Letícia. Identidade e representação no bolsonarismo: corpo digital do rei, bivalência e conservadorismo-neoliberalismo e pessoa. Revista de Antropologia (USP), São Paulo (online), n. 62, v. 3, 2019. pp. 530-557. Disponível em: https://doi.org/10.11606/21790892.ra.2019.165232. Acesso: 29 set 2020.

Como vencer uma eleição sem sair de casa: a ascensão do populismo digital no Brasil. Rev. Internet \& Sociedade, n. 1, v. 1, fev, 2020a. Disponível em: https://revista.internetlab.org.br/serifcomo-vencer-uma-eleicao-sem-sair-de-casa-serif-aascensao-do-populismo-digital-no-brasil/. Acesso: 31 ago 2020.

Como as mídias sociais proporcionam uma política populista: observações sobre liminaridade com base no caso brasileiro. Trabalho em Linguística Aplicada, Campinas, n. 59, v. 1, jan/abr 2020b. pp. 404-427. Disponível em: http://dx.doi.org/10.1590/01031813686191620200410. Acesso: 29 set 2020.

GELL, Alfred. Arte e agência (Coleção Argonautas). Tradução de Jamille Pinheiro Dias. Ubu Editora (Kindle), 2018 [1998]. HINE, Christine. Ethnography for internet: Embedded, embodied and everyday. Bloomsbury Publishing Plc, London, New Delhi, New York, Sydney, 2015. 
Rev. Interd. em Cult. e Soc. (RICS), São Luís, v. 6, n. 2, p. 156-173, jul./dez. 2020 ISSN eletrônico: $2447-6498$

JAMES, William. Pragmatismo e outros textos. Tradução Jorge Caetano da Silva, Pablo Rubén Mariconda. São Paulo, Abril Cultural, 1979. Os pensadores.

KECK, Frédéric; KELLY, Ann H.; LYNTERIS, Christos. Introduction: the anthropology of epidemics. In The anthropology of epidemics. London: Routledge, 2019.

KNOR-CETINA, Karin. The Ethnographic Study of Scientific Work: Towards a Constructivism Interpretation of Science. In: KNOR-CETINA, Karin. (ed.). Perspectives on the Social Study of Science. London, Sage, 1983. pp. 115-140. Disponível em: <https://dnb.info/1101582359/34> . Acesso: 24 jan. 2018

LATOUR, Bruno. A esperança de pandora: ensaios sobre a realidade dos estudos científicos. Tradução de Gibson César Cardoso de Sousa. Bauru, SP, EDUSC, 2001. (Coleção filosofia e política).

Ciência em ação: como seguir cientistas e engenheiros sociedade afora. São Paulo. Editora UNESP, 2000.

Investigação sobre os modos de existência: uma antropologia dos modernos. Tradução Alexandre Agabiti Fernandez, Petrópolis, RJ, Vozes, 2019. Coleção Antropologia.

Reagregando o social: uma introdução à Teoria do Ator-Rede. Salvador, EDUFBA, 2012; BAURU, São Paulo, 2012.

LEITÃO, Débora K.; GOMES, Laura Graziela. Etnografia em ambientes digitais: perambulações, acompanhamentos e imersões. 2017. Disponível em: http://www.revistas.uff.br/index.php/antropolitica/article/view/546. Acesso: 31 ago 2020.

MACPHAIL, Theresa. The predictable unpredictability of viruses and the concept of 'strategic uncertainty'. In: The viral network: a pathography of the H1N1 influenza pandemic. Ithaca: Cornell University Press, 2014, p. 132-151.

MILLER, Daniel. Etnografia on e off-line: cibercafés em Trinidad. Horizontes Antropológicos, Porto Alegre, ano 10, n 21, jan/jun, 2004. P. 41-65. Disponível em: https://www.scielo.br/scielo.php?script=sci_arttext\&pid=S0104-71832004000100003. Acesso: 31 ago 2020. NADING, Alex. Humans, animals, and health: from ecology to entanglement. Environment and Society, v.4, i. 1, 2013. Pp. 60-78. Disponível em: https://doi.org/10.3167/ares.2013.040105. Acesso: 29 set 2020.

PAXSON, Heather. Post-Pasteurian cultures: the microbiopolitics of Raw-Milk Cheese in the United States. Cultural Anthropology, v. 23, n. 1, feb. 2008. pp. 15-47. Disponível em: http://www.jstor.org/stable/20484494. Acesso: 29 set 2020.

GHANDI, Rajesh T.; LYNCH, Jonh B.; RIO, Carlos del. Mil dor moderate Covid-19. The New England Journal of Medicine, apr 2020. Disponível em:

https://www.nejm.org/doi/10.1056/NEJMcp2009249. Acesso: 29 set 2020.

RAMOS, Jair de Souza.; FREITAS, Eliane Tânia. Etnografia digital. Dossiê. Rev. Antropológica. n. 42m, Niterói, p. 8-15, 1 sem, 2017. Disponível em: 
Rev. Interd. em Cult. e Soc. (RICS), São Luís, v. 6, n. 2, p. 156-173, jul./dez. 2020

ISSN eletrônico: $2447-6498$

http://repositorio.unicamp.br/bitstream/REPOSIP/250809/1/Ramos_ElianedeSouza_M.pdf. Acesso 31 ago 2020.

SCOTT, Russel Perry; LIRA, Luciana; MATOS, Silvana (Orgs.). Práticas sociais no epicentro da epidemia de Zika. Recife, Editora UFPE, 2020.

SILVA, Geyza Kelly A. da. Teias de alianças, lealdade e dependência: tabajaras e potiguaras aliados/aldeados na capitania de Pernambuco. Clio - Série Rev. de Pesquisa Histórica, v. 25, n. 2, 2007. Disponível em:

https://periodicos.ufpe.br/revistas/revistaclio/article/view/24729. Acesso: 29 set 2020.

SEGATA, Jean.; MASTRANGELO, Andrea. A biossegurança e suas antropologias. Hor. Antropológicos, v. 57, mai/ago 2020. pp. 7-25. Dossiê (Apresentação). Disponível em: http://dx.doi.org/10.1590/S0104-71832020000200001. Acesso: 29 set 2020. 